\title{
ANALISIS PERBANDINGAN PORTOFOLIO OPTIMAL PADA SAHAM SRI KEHATI DENGAN MENGGUNAKAN MODEL INDEKS TUNGGAL DAN MODEL RANDOM
}

\author{
Maya Novitasari $^{1)}$, Heidy Paramitha Devi ${ }^{2)}$, Rollis Ayu Ditasari ${ }^{3)}$ \\ Universitas PGRI Madiun \\ maya.novitasari@unipma.ac.id \\ heidypd88@unipma.ac.id \\ rollis_ayuditasari@yahoo.co.id
}

\begin{abstract}
Abstract; The purpose of this study is to provide empirical evidence that the determination of a stock portfolio using a single index model can provide optimal returns compared with the determination of stock portfolio using a random model. The sample in this research is 25 shares joined in SRI-KEHATI selected using purposive sampling. The data analysis technique used the average test for two independent samples (Mann Whitney Test $(U$ Test)). The results showed that the determination of the stock portfolio using a single index model can provide optimal return compared to the determination of stock portfolio using random model.
\end{abstract}

Keywords:Portfolio, Single Index Model, Random

\begin{abstract}
Abstrak
Tujuan dari penelitian ini adalah memberikan bukti empiris bahwa penentuan portofolio saham menggunakan model indeks tunggal dapat memberikan return yang optimal dibandingkan dengan penentuan portofolio saham menggunakan model random.Sampel dalam penelitian ini adalah 25 saham yang tergabung dalam SRI-KEHATI yang dipilih menggunakan purposive sampling.Teknik analisis data menggunakan uji rata-rata untuk dua sampel independen (Uji Mann Whitney (U Test)). Hasil penelitian menunjukkan bahwa penentuan portofolio saham menggunakan model indeks tunggal dapat memberikan return yang optimal dibandingkan dengan penentuan portofolio saham menggunakan model random.
\end{abstract}

Kata Kunci:Portofolio, Model Indeks Tunggal, Random.

\section{PENDAHULUAN}

Keberadaan pasar modal sangat membantu para pelaku ekonomi dalam mencari alternatif pendanaan kegiatan usaha dan juga para investor yang ingin menanamkan dananya. Para investor lebih suka menanamkan dananya di bank dalam bentuk deposito. Hal ini

disebabkan karena semakin menurunnya tingkat suku bunga deposito bank. Akan tetapi untuk menginvestasikan dana di Bursa Efek tidaklah mudah karena investor akan diharapkan pada tingkat risiko yang ditanggung. Oleh sebab itu sebelum investor menginvestasikan dananya, 
terlebih dahulu perlu dilakukan analisis terhadap berapa tingkat risiko yang bersedia ditanggung oleh investor dan diperusahaan mana dana tersebut akan diinvestasikan.

Pada penelitian ini, yang akan diteliti adalah portofolio mana yang memiliki tingkat keuntungan yang tinggi dengan risiko tertentu serta meminimalkan risiko tersebut. Di Bursa Efek Indonesia, saat ini memiliki 11 jenis indeks harga saham. Dimana salah satu indeks yang saat ini cukup menarik investor adalah SRI KEHATI Indeks.

Indeks SRI KEHATI merupakan satu-satunya indeks hijau (green index) yang listing di pasar modal dan pertama keberadaannya di Asia Tenggara. Karena menggunakan metodologi unik dan inovatif guna mengukur praktik perusahaan dan menerjemahkannya ke dalam sistem rating untuk memilih 25 perusahaan di BEI.

Alternatif pemilihan saham
dan penentuan portofolio dapat
dilakukan dengan menggunakan
berbagai alat analisis salah satunya
dengan menggunakan model indeks

tunggal. Model indeks tunggal banyak dipergunakan sebagai alat analisis untuk mendapatkan portofolio yang efisien, selain modelnya sederhana juga mudah untuk di operasikan. Investor harus bersikap rasional dalam menghadapi pasar jual beli saham. Namun investor terkadang sering kali hanya mengikuti keinginan individu, ikutikutan atau gambling dalam menentukan portofolio. Hal ini lebih dikenal dengan penentuan portofolio secara random atau acak (tanpa memperhatikan karakteristik investasi secara relevan).

Berdasarkan latar belakang yang telah diuraikan, peneliti mengambil rumusan masalah sebagai berikut :

“Apakah penentuan portofolio saham menggunakan model indeks tunggal dapat memberikan return yang optimal dibandingkan dengan penentuan portofolio saham menggunakan model random?"

Sesuai dengan permasalahan dan pertanyaan penelitian yang diajukan, maka tujuan penelitian adalah untuk memberikan bukti 
empiris penentuan portofolio

saham menggunakan model indeks tunggal dapat memberikan return yang optimal dibandingkan dengan penentuan portofolio saham menggunakan model random.

\section{KAJIAN PUSTAKA}

\section{Pasar Modal}

Berdasarkan UU Pasar Modal No.8 Tahun 1995 dinyatakan bahwa pasar modal,yaitu suatu tempat berlangsungnya kegiatan yang berkaitan dengan penawaran umum dan perdagangan efek,serta lembaga dan profesi yang berkaitan dengan efek. Pasar modal merupakan tempat untuk mempertemukan pihak yang membutuhkan dana jangka panjang dan pihak yang membutuhkan sarana investasi pada instrumen financial (saham, obligasi, reksa dana dan lainlain).

\section{Investasi}

Menurut Jogiyanto (2014: 5), investasi adalah Penundaan konsumsi sekarang untuk dimasukkan ke aktiva produktif selama periode waktu yang tertentu.
Menurut Ahmad (2004: 3), investasi adalah menempatkan uang atau dana dengan harapan untuk memperoleh tambahan atau keuntungan tertentu atas uang atau dana tersebut.

Menurut PSAK Nomor 13 dalam standar Akuntansi Keuangan per 1 Oktober 2004 investasi adalah suatu aktiva yang digunakan perusahaan untuk pertumbuhan kekayaan (accretion of wealth) melalui distribusi hasil investasi (seperti bunga, royalti, dividen, dan uang sewa),untuk apresiasi nilai investasi,atau untuk manfaat lain bagi perusahaan yang berinvestasi seperti manfaat yang diperoleh melalui hubungan perdagangan.

\section{Saham}

Saham adalah tanda bukti memiliki perusahaan dimana pemiliknya disebut juga sebagai pemegang saham (shareholder atau stockholder) (Samsul, 2006:45).

\section{Portofolio}

Portofolio merupakan investasi dalam berbagai instrumen keuangan 
(diversifikasi). Portofolio penelitian yang digunakan untuk dimaksudkan untuk mengurangi membandingkan antara dua kelompok resiko investasi dengan cara atau lebih dari suatu variabel tertentu. menyebarkan dana ke berbagai aset Adapun populasi dalam penelitian ini yang berbeda, sehingga jika satu aset menderita kerugian sementara aset lainnya tidak menderita kerugian, maka nilai investasi kita tidak hilang semua. (Samsul, 2006 : 301).

\section{Hipotesis}

$\mathrm{H}_{0}$ : Penentuan portofolio saham menggunakan model indeks tunggal dapat memberikan return yang tidak optimal dibandingkan dengan penentuan portofolio saham menggunakan model random.

$\mathrm{H}_{1}$ : Penentuan portofolio saham menggunakan model indeks tunggal dapat memberikan return yang optimal dibandingkan dengan penentuan portofolio saham menggunakan model random

\section{METODE PENELITIAN}

Jenis penelitian yang
dilakukan oleh penulis adalah
penelitian komparatif, yaitu jenis
yaitu semua saham (perusahaan) yang masuk dalam saham SRI KEHATI selama periode Mei 2016-April 2017. Dalam penelitian ini, teknik pengambilan sampel menggunakan teknik purposive sampling, artinya yang dijadikan sampel adalah sampel yang memenuhi criteria sampel tertentu sesuai dengan yang dikehendaki peneliti. Dalam penelitian ini, saham-saham yang dijadikan sampel harus memenuhi kriteria sebagai berikut:

1. Perusahaan-perusahaan tersebut terdaftar di BEI.

2. Perusahaan termasuk ke dalam kelompok saham SRI KEHATI.

3. Perusahaan-perusahaan tersebut mempunyai kelengkapan data perdagangan selama periode penelitian mulai dari Mei 2016 sampai dengan April 2017.

Variabel-variabel dalam penelitian ini meliputi:

1) Model Indeks Tunggal 
Model indeks tunggal yaitu Berikut langkah-langkah dalam dengan membandingkan antara membentuk portofolio menggunakan excess return to beta (ERB) yang model indeks tunggal adalah:

merupakan kelebihan pengembalian atas tingkat keuntungan bebas risiko (risk free rate) pada aset lain dan cut off rate (Ci) (Rachmanto, 2002).

2) Model Random

Diversifikasi secara random (random atau native diversificstion) merupskan pembentukan portofolio dengan memilih sekuritas-sekuritas secara acak tanpa memperhatikan karakteristik dari investasi yang relevan seperti misalnya return dari sekuritas itu sendiri (Jogiyanto, 2016: 338-339).

HASIL DAN PEMBAHASAN Analisis Model Indeks Tunggal
1) Menghitung nilai return realisasi (Ri) masing-masing saham setiap harinya dengan rumus :

$$
R_{i}=\ln \frac{P_{t}}{P_{t-1}}
$$

Keterangan:

$$
\begin{aligned}
R_{\tilde{i}}= & \text { Return saham ke } \mathrm{i} \\
P_{t}= & \text { Harga saham periode } \mathrm{t} \\
P_{t-1}= & \text { Harga saham periode } \\
& \text { sebelumnya }
\end{aligned}
$$

2) Menghitung return ekspektasi $(\mathrm{E}(\mathrm{R}))$ masing-masing saham.

$$
\mathrm{E}(\mathrm{Ri})=\frac{\sum R i}{n}
$$

Keterangan:

$R i=$ Return saham $\mathrm{i}$

$\mathrm{E}(\mathrm{Ri})=$ Tingkat keuntungan yang diharapkan oleh investor

$N=$ Jumlah periode

Sumber: Jogiyanto (2014: 281) 
Tabel 1.Nilai Expected Return dan Varian 23 Saham SRI KEHATI Periode Penelitian Mei2016- April2017

\begin{tabular}{|c|c|c|c|}
\hline No. & Kode Saham & $\mathbf{E}(\mathbf{R i})$ & Variance \\
\hline 1 & AALI & -0.0000806265 & 0.0003627906 \\
\hline 2 & ADHI & -0.0004064532 & 0.0005937881 \\
\hline 3 & ASII & 0.0013562822 & 0.0003614849 \\
\hline 4 & BBCA & 0.0013237454 & 0.0001150200 \\
\hline 5 & $\mathrm{BBNI}$ & 0.0014962058 & 0.0002786022 \\
\hline 6 & BBRI & 0.0010235136 & 0.0002335623 \\
\hline 7 & BDMN & 0.0018297176 & 0.0004502688 \\
\hline 8 & BMRI & 0.0009492605 & 0.0003141850 \\
\hline 9 & BSDE & 0.0000730738 & 0.0004186168 \\
\hline 10 & GIAA & -0.0005504515 & 0.0004373936 \\
\hline 11 & INDF & 0.0008217436 & 0.0003151195 \\
\hline 12 & JPFA & 0.0023382683 & 0.0008961967 \\
\hline 13 & JSMR & -0.0005090423 & 0.0002903442 \\
\hline 14 & KLBF & 0.0007388717 & 0.0003097309 \\
\hline 15 & LSIP & -0.0001529585 & 0.0004862916 \\
\hline 16 & PGAS & 0.0000338569 & 0.0007037075 \\
\hline 17 & PJAA & -0.0000372864 & 0.0006669325 \\
\hline 18 & SMCB & -0.0003612168 & 0.0004363265 \\
\hline 19 & SMGR & -0.0002645699 & 0.0004203692 \\
\hline 20 & TINS & 0.0012664447 & 0.0009187427 \\
\hline 21 & TLKM & 0.0009856082 & 0.0004947762 \\
\hline 22 & UNTR & 0.0027141251 & 0.0006236104 \\
\hline 23 & UNVR & 0.0002641815 & 0.0001643221 \\
\hline 24 & WIKA & 0.0001365652 & 0.0005692498 \\
\hline 25 & WSKT & 0.0002581611 & 0.0003636394 \\
\hline
\end{tabular}


3) Menghitung return pasar $\left(\mathrm{R}_{\mathrm{m}}\right)$ periode 2016-2017.

$$
R_{m}=\frac{I H S G_{t}-I H S G_{t-1}}{I H S G_{t-1}}
$$

Keterangan:

$R_{m} \quad=\quad$ Return pasar pada periode tertentu

$I H S G_{t}=$ Indeks harga saham gabungan pada periode tertentu

$I H S G_{t-1}=$ Indeks harga saham gabungan pada periode sebelumnya

Sumber: Jogiyanto (2014: 153)

4) Menghitung return ekspektasi pasar $(\mathrm{E}(\mathrm{Rm}))$.

$$
E\left(R_{M}\right)=\frac{\sum R_{M}}{n}
$$

Keterangan:

$$
\begin{array}{ll}
E\left(R_{M}\right)=\begin{array}{l}
\text { Tingkat } \\
\text { keuntungan pasar } \\
\text { yang diharapkan }
\end{array} \\
R_{M} \quad=\begin{array}{l}
\text { Return pasar pada } \\
\text { periode tertentu }
\end{array} \\
N \quad=\text { Jumlah periode }
\end{array}
$$

5) Menghitung beta dan alpha dengan rumus:

$$
\begin{aligned}
& \beta i=\left(\frac{\text { oim }}{\sigma i m}\right) \\
& \alpha=\mathrm{E}\left(\mathrm{R}_{1}\right)-\left(\beta \cdot \mathrm{E}\left(\mathrm{R}_{\mathrm{M}}\right)\right)
\end{aligned}
$$

Sumber: Tandelilin (2010:132) dalam Wibowo,et al (2014)

6) Menghitung risiko investasi dengan rumus:

a. Menghitung risiko unik $\left(\sigma_{\mathrm{ei}}{ }^{2}\right)$

$$
\begin{gathered}
e i=R i-\alpha i-(\beta i . R m) \\
\sigma e i^{2}=\frac{\sum_{i=1}^{n}\left(e i-E(e i)^{2}\right.}{n-1}
\end{gathered}
$$

Sumber: Tandelilin (2010:178)

dalam Wibowo, et al (2014).

b. Menghitung resiko sekuritas

$$
\sigma_{i}^{2}=\beta_{i}^{2} \cdot \sigma_{M}^{2}+\sigma_{e i}^{2}
$$

\begin{tabular}{|c|c|c|}
\hline No. & Bulan & $\%$ \\
\hline 1 & May & 5.50 \\
\hline 2 & June & 5.25 \\
\hline 3 & July & 5.25 \\
\hline 4 & August & 5.25 \\
\hline 5 & September & 5.00 \\
\hline 6 & October & 4.75 \\
\hline 7 & November & 4.75 \\
\hline 8 & December & 4.75 \\
\hline 9 & January & 4.75 \\
\hline 10 & February & 4.75 \\
\hline 11 & Maret & 4.75 \\
\hline 12 & April & 4.75 \\
\hline \multicolumn{2}{|c|}{ Jumlah } & 59.50 \\
\hline \multicolumn{2}{|c|}{ Rata-rata/tahun } & 4.96 \\
\hline \multicolumn{2}{|c|}{ Rata-rata/hari } & 0.01 \\
\hline & $\mathbf{R B r}$ & 0.000137731 \\
\hline
\end{tabular}

Sumber: Hartono (2013: 346) daam Wibowo, et al (2014)

7) Menentukan tingkat pengembalian bebas resiko ( $\mathrm{RBr}$ ) yang akan menggunakan rata-rata $\mathrm{BI}$ rate/ $\mathrm{BI}$ 7day Repo Rate periode 20162017.

$$
R_{B R}=\frac{\sum S B I}{n}
$$

Keterangan:

$$
\begin{array}{ll}
R_{B R} & =\text { Return Bebas Risiko } \\
\sum_{S B I} & =\text { Jumlah suku bunga SBI } \\
& \text { pada periode pengamatan } \\
n & =\text { Jumlah periode perhitungan } \\
& \text { Tabel 2. Suku Bunga SBI } \\
\hline
\end{array}
$$

\section{BI 7-day (Reverse) Repo Rate}


8) Menghitung excess return to beta (ERBi) dengan rumus:

$$
\begin{array}{|c|}
\mathrm{ERB}_{\mathrm{i}}=\frac{E(R)_{i}-R_{B R}}{\beta_{i}} \\
\text { Sumber: Jogiyanto (2014: 430) }
\end{array}
$$

Keterangan:

$$
\begin{aligned}
& \mathrm{ERB}_{i}=\text { Excess return to beta } \\
& \text { pada sekuritas i } \\
& E(R)_{i}=\text { Expectedreturn } \\
& R_{B R}=\text { Return bebas resiko } \\
& \beta_{i}=\text { Beta Saham }
\end{aligned}
$$

9) Menyusun peringkat saham berdasarkan ERB tertinggi sampai terendah.

Tabel 3. Nilai ERB

\begin{tabular}{clr}
\hline No. & $\begin{array}{c}\text { Kode } \\
\text { Saham }\end{array}$ & \multicolumn{1}{l}{ ERB } \\
\hline 1 & AALI & -0.0005591293 \\
2 & ADHI & -0.0005990623 \\
3 & ASII & 0.0009295616 \\
4 & BBCA & 0.0018210634 \\
5 & BBNI & 0.0013159310 \\
6 & BBRI & 0.0008468395 \\
7 & BDMN & 0.0019991852 \\
8 & BMRI & 0.0006746144 \\
9 & BSDE & -0.0000545732 \\
10 & GIAA & -0.0013743626 \\
11 & INDF & 0.0006425802 \\
12 & JPFA & 0.0031956957 \\
13 & JSMR & -0.0008592407 \\
14 & KLBF & 0.0006498958 \\
15 & LSIP & -0.0005962160 \\
16 & PGAS & -0.0000855614 \\
17 & PJAA & -0.0010524191 \\
18 & SMCB & -0.0008389002 \\
19 & SMGR & -0.0003579982 \\
20 & TINS & 0.0010832557 \\
21 & TLKM & 0.0007258827
\end{tabular}

\begin{tabular}{llr}
\hline No. & $\begin{array}{c}\text { Kode } \\
\text { Saham }\end{array}$ & \\
\hline 22 & UNTR & 0.0022976822 \\
23 & UNVR & 0.0001714513 \\
24 & WIKA & -0.0000013126 \\
25 & WSKT & 0.0001400508 \\
\hline
\end{tabular}

10) Menghitung nilai Ai dan Bi untuk masing-masing sekuritas ke-i.

$$
\begin{aligned}
& \mathrm{A}_{\mathrm{i}}=\frac{\left[E\left(R_{i}\right)-R_{B R}\right] \cdot \beta_{i}}{\sigma_{e i}^{2}} \\
& B_{i}=\frac{\beta_{i}^{2}}{\sigma_{e i}^{2}}
\end{aligned}
$$

Sumber: Hartono (2014: 431)

11) Menghitung nilai $\mathrm{Ci}$, yaitu nilai $\mathrm{C}$ untuk sekuritas ke-i yang dihitung dari akumulasi nilai-nilai A1 sampai $\mathrm{Ai}$ dan nilai-nilai $\mathrm{B} 1$ sampai Bi.

$$
\mathrm{C}_{\mathrm{i}}=\frac{\sigma m^{2} \sum_{j=1}^{i} \frac{[E(R i)-R b r] \beta i}{\sigma e i^{2}}}{1+\sigma m^{2} \sum_{j=1}^{i} \frac{\beta i^{2}}{\sigma e i^{2}}}
$$

Sumber: Jogiyanto (2014: 432)

12) Menentukan unique-cut-off point $\left(\mathrm{C}^{*}\right)$.

Untuk mencari $\mathrm{C}^{*}$, amati nilai $\mathrm{Ci}$ pada saat saham-saham yang masih masuk dalam portofolio optimal dan kemudian berubah menjadi keluar dari portofolio optimal. Nilai Ci yang merupakan nilai optimal itulah yang merupakan $C^{*}$. Nilai $C^{*}$ merupakan nilai $\mathrm{Ci}$ tertinggi pada kelompok saham-saham yang masuk dalam portofolio optimal 


\begin{tabular}{|c|c|c|c|c|}
\hline \multicolumn{5}{|c|}{ Tabel 4. Nilai $A_{i}, B_{i}, C_{i}$} \\
\hline No. & Kode Saham & $\mathbf{A}_{\mathbf{i}}$ & $\mathbf{B}_{\mathbf{i}}$ & $\mathbf{C}_{\mathbf{i}}$ \\
\hline 1 & AALI & -0.2458674940 & 439.7328316140 & 0.0000335220 \\
\hline 2 & ADHI & -0.9741187675 & 1626.0726546756 & 0.0001239549 \\
\hline 3 & ASII & 8.7901249771 & 9456.2046207885 & 0.0007219453 \\
\hline 4 & BBCA & 10.9331254077 & 6003.7037371159 & 0.0004587682 \\
\hline 5 & $\mathrm{BBNI}$ & 8.3914542455 & 6376.8193177833 & 0.0004870338 \\
\hline 6 & BBRI & 7.7784813484 & 9185.3074458581 & 0.0007012053 \\
\hline 7 & BDMN & 3.8151881678 & 1908.3715407143 & 0.0001458526 \\
\hline 8 & BMRI & 5.9962037241 & 8888.3421287694 & 0.0006784183 \\
\hline 9 & BSDE & -0.2818694970 & 5164.9805459519 & 0.0003939389 \\
\hline 10 & GIAA & -0.8380885429 & 609.8016318979 & 0.0000464489 \\
\hline 11 & INDF & 3.7037735322 & 5763.9082362622 & 0.0004399263 \\
\hline 12 & JPFA & 1.7898462145 & 560.0803003912 & 0.0000428568 \\
\hline 13 & JSMR & -2.1068772544 & 2452.0220587902 & 0.0001868680 \\
\hline 14 & KLBF & 2.5248240464 & 3884.9676511357 & 0.0002965196 \\
\hline 15 & LSIP & -0.3071534824 & 515.1715040289 & 0.0000392714 \\
\hline 16 & PGAS & -0.2294830552 & 2682.0877914040 & 0.0002045595 \\
\hline 17 & PJAA & -0.0438310935 & 41.6479444049 & 0.0000031734 \\
\hline 18 & SMCB & -0.7431514399 & 885.8639464330 & 0.0000675128 \\
\hline 19 & SMGR & -1.5682827152 & 4380.6994720041 & 0.0003340195 \\
\hline 20 & TINS & 1.4606556612 & 1348.3941983554 & 0.0001029606 \\
\hline 21 & TLKM & 8.2547458373 & 11372.0113180893 & 0.0008680331 \\
\hline 22 & UNTR & 5.8950112162 & 2565.6338115178 & 0.0001961441 \\
\hline 23 & UNVR & 0.8681737152 & 5063.6744184495 & 0.0003862995 \\
\hline 24 & WIKA & -0.0021293750 & 1622.2047671459 & 0.0001237340 \\
\hline 25 & WSKT & 0.3617217590 & 2582.7887726650 & 0.0001970306 \\
\hline
\end{tabular}

13) Menentukan portofolio optimal dengan ukuran ERBi $\geq C^{*}$.

Tabel 5. Kandidat Portofolio Menggunakan model Indeks Tunggal

\begin{tabular}{clllc}
\hline No. & $\begin{array}{c}\text { Kode } \\
\text { Perusahaan }\end{array}$ & ERb & Ci \\
\hline 1. & ASII & 0.0009295616 & $>$ & 0.0007219453 \\
2. & BBCA & 0.0018210634 & $>$ & 0.0004587682 \\
3. & BBNI & 0.0013159310 & $>0.0004870338$ \\
4. & BBRI & 0.0008468395 & $>$ & 0.0007012053 \\
5. & BDMN & 0.0002090652 & $>$ & 0.0001455920 \\
6. & INDF & 0.0006425802 & $>$ & 0.0004399263 \\
7. & JPFA & 0.0009954931 & $>$ & 0.0000427628 \\
8. & KLBF & 0.0006498958 & $>0.0002965196$ \\
9. & TINS & 0.0010832557 & $>0.0001029606$ \\
10. & UNTR & 0.0009465320 & $>0.0001958797$ \\
\hline
\end{tabular}


14) Menghitung proporsi dari masingmasing sekuritas.

$$
\mathrm{W}_{\mathrm{i}}=\frac{z_{i}}{\sum_{j=1}^{k} z_{j}}
$$

Dengan nilai Zi sebesar:

$$
\mathrm{Z}_{\mathrm{i}}=\frac{\beta_{i}}{\sigma_{\text {ei }}^{\mathrm{a}}}\left(\mathrm{ERB}_{\mathrm{i}}-\mathrm{C}^{*}\right)
$$

Sumber:Jogiyanto (2010:366-367) dalam Dahlan (2015)

15)Menghitung nilai returnportofolio dari kombinasi portofolio yang telah terpilih dengan rumus:

$$
\mathrm{E}\left(\mathrm{R}_{\mathrm{p}}\right)=\alpha_{\mathrm{p}}+\beta_{\mathrm{p}} \cdot \mathrm{E}\left(\mathrm{R}_{\mathrm{m}}\right)
$$

Sumber: Jogiyanto (2013: 356) dalam Wibowo (2014)

Dengan perhitungan $\alpha_{\mathrm{p} d a n} \beta_{\mathrm{p}}$ sebagai berikut:

$$
\begin{aligned}
& \alpha_{\mathrm{p}}=\sum_{i=1}^{n} w_{i} . \\
& \alpha_{\mathrm{i}} \\
& \beta_{\mathrm{p}}=\sum_{i=1}^{n} w_{\mathrm{I}} . \\
& \beta_{\mathrm{i}}
\end{aligned}
$$

Sumber:Hartono (2013: 357) dalam Wibowo (2014)

16. Menghitung risiko portofolio dari kombinasi portofolio yang telah terpilih dengan rumus:

$\sigma \mathrm{p}^{2}=\beta \mathrm{p}^{2}$
$\sigma \mathrm{M}^{2}$

Sumber:Hartono (2013: 361) dalam Wibowo (2014)

\section{Analisis Model Random}

Pemilihan kandidat portofolio model random dilakukan dengan bantuan program Microsoft Excel dengan rumus "RAND". Model ini memungkinkan setiap portofolio mempunyai kesempatan yang sama untuk menjadi kandidat. Berdasarkan pemilihan portofolio menggunakan model indeks tunggal diperoleh 10 portofolio, maka peneliti juga akan memilih 10 portofolio yang akan dijadikan kandidat model random. Pengacakan portofolio yang menjadi model random diperoleh kandidat sebagai berikut:

Tabel 6. Kandidat Portofolio Model Random

\begin{tabular}{clr}
\hline No. & $\begin{array}{c}\text { Kode } \\
\text { Persh. }\end{array}$ & $\mathbf{E}(\mathbf{R i})$ \\
\hline 1. & PJAA & -0.0000372864 \\
2. & PGAS & 0.0000338569 \\
3. & ADHI & -0.0004064532 \\
4. & UNVR & 0.0002641815 \\
5. & LSIP & -0.0001529585 \\
6. & BBCA & 0.0013237454 \\
7. & BDMN & 0.0018297176 \\
8. & SMCB & -0.0003612168 \\
9. & UNTR & 0.0027141251 \\
10. & INDF & 0.0008217436 \\
\hline & & \\
\hline
\end{tabular}

\section{Pengujian Hipotesis}

Pengujian hipotesis dilakukan dengan Uji rata-rata untuk dua sampel independen (Uji Mann Whitney ( $U$ Test)). Sebelum melakukan pengujian hipotesis terlebih dahulu dapat dirumuskan hipotesis sebagai berikut:

$$
\begin{aligned}
& \mathrm{H}_{0} \text { : Penentuan portofolio } \\
& \text { saham menggunakan } \\
& \text { model indeks tunggal } \\
& \text { dapat memberikan } \\
& \text { return yang tidak } \\
& \text { optimal dibandingkan } \\
& \text { dengan penentuan } \\
& \text { portofolio saham } \\
& \text { menggunakan model } \\
& \text { random. } \\
& \mathrm{H}_{1} \text { : Penentuan portofolio } \\
& \text { saham menggunakan }
\end{aligned}
$$


model indeks tunggal

dapat memberikan

return yang optimal

dibandingkan dengan

penentuan portofolio

saham menggunakan

model random.

Kriteria pengambilan

keputusan dalam uji Mann Whitney

(U Test) dengan tingkat signifikansi

0,05 adalah sebagai berikut:
- Apabila $\mathrm{P}_{\text {value }}$ (Asymp. sig. (2tailed) $<0,05$ maka $\mathrm{H}_{0}$ ditolak

- Apabila $\mathrm{P}_{\text {value }}$ (Asymp. sig. (2tailed)) > 0,05 maka $\mathrm{H}_{0}$ diterima

Berikut hasil pengujian hipotesis menggunakan program SPSS dapat dilihat pada tabel berikut:

Tabel 7. Hasil Uji Mann Whitney (U Test) Mean Rank

\begin{tabular}{llrrr}
\hline & \multicolumn{3}{c}{ Ranks } & \\
\hline & Penentuan_Portofolio & N & Mean Rank & Sum of Ranks \\
Return_Por & Indeks Tunggal & 10 & 13.20 & 132.00 \\
tofolio & Random & 10 & 7.80 & 78.00 \\
& Total & 20 & & \\
& & &
\end{tabular}

Sumber: Output SPSS ver 16

Tabel di atas menunjukkan Mean Rank atau rata-rata peringkat tiap kelompok.Pada kelompok pertama (Indeks Tunggal) memiliki nilai rerata peringkat sebesar 13.20 lebih besar daripada rerata peringkat kelompok kedua (Random) yaitu sebesar 7.80 .

Tabel 8.Hasil Uji Mann Whitney (U Test) P Value

\begin{tabular}{lr}
\multicolumn{2}{c}{ Test Statistics $^{\mathbf{b}}$} \\
\hline Mann-Whitney U & Return_Portofolio \\
Wilcoxon W & 23.000 \\
Z & 78.000 \\
Asymp. Sig. (2-tailed) & -2.044 \\
Exact Sig. [2*(1-tailed Sig.)] & .041 \\
\hline a. Not corrected for ties. & $.043^{\text {a }}$ \\
b. Grouping Variable: Penentuan_Portofolio &
\end{tabular}

Sumber: Output SPSS ver 16 
Tabel diatas menunjukkan nilai $U$ sebesar 23.000 dan nilai $\mathrm{W}$ sebesar 78.000.Apabila dikonversikan ke nilai $\mathrm{Z}$ maka besarnya -2.044.Nilai sig atau $\mathrm{P}$ Value sebesar 0,041. Ternyata nilai $\mathrm{P}$ Value kurang dari probabilitas $(0,041<0,05)$ maka $\mathrm{H}_{0}$ ditolak artinya Penentuan portofolio saham menggunakan model indeks tunggal dapat memberikan return yang optimal dibandingkan dengan penentuan portofolio saham menggunakan model random.

\section{Pembahasan}

Setelah dilakukan uji hipotesis diketahui bahwa penentuan portofolio saham menggunakan model indeks tunggal dapat memberikan return yang optimal dibandingkan dengan penentuan portofolio saham menggunakan model random. Hasil penelitian ini sesuai dengan penelitian yang dilakukanolehLinda Ratna Sari (2015)meneliti perbandingan return saham kompas 100 menggunakan model indeks tunggal dan model random menunjukkan bahwa penentuan portofolio saham menggunakan model indeks tunggal dapat memberikan return yang optimal dibandingkan dengan penentuan portofolio saham menggunakan model random. Penelitian tersebut didukung juga dengan penelitian yang dilakukan oleh Ni Putu Nonik Hariasih dan Dewa Gede Wirama (2016) dengan hasil penelitian yang menyatakan bahwa terdapat perbedaan return portofolio menggunakan model indeks tunggal dan model random. Penentuan portofolio optimal menggunakan model indeks tunggal dapat memberikan return yang lebih tinggi dibandingkan dengan portofolio model random.

\section{DAFTAR PUSTAKA}

Ahmad,Kamaruddin.2004. DasarDasar Manajemen Investasi dan Portofolio. Edisi Revisi. Jakarta: PT. Rineka Cipta,Jakarta.

Darmawan,I Putu Putra Adi dan Purnawati,Ni Ketut. 2015. Pembentukan Portofolio Optimal Pada Saham-Saham di Indeks LQ-45 dengan Menggunakan Model Indeks Tunggal. E-Jurnal Manajemen, Unud, Vol.4, No.12.

Dewi,Vera Intanie dan Oriana,Felisca. 2014. Indeks Sri-Kehati Dan Reaksi Harga Saham Emiten Terhadap Pengumuman Indeks SriKehati (Studi Kasus pada Indeks SRI-KEHATI). Lembaga Penelitian dan Pengabdian kepada Masyarakat Universitas Katolik Parahyangan.

Fahmi,Irham dan Hadi, Yovi Lavianti. 2011. Teori Portofolio dan Analisis Investasi Teori dan Soal Jawab.

Ghozali,Imam. 2013. Desain Penelitian Kuantitatif dan Kualitatif untuk Akuntansi, Bisnis, dan ilmu Sosial Lainnya. Semarang: Penerbit Yoga Pratama.

Sugiyono. 2007. Statistika untuk Penelitian. Bandung: Alfabeta. 
Glinmourinse,Disfiyant. 2014. Sri Kehati Satu-Satunya Green Index di Pasar

Modal.

https://ekbis.sindonews.com/re ad/873961/32/sri-kehati-satusatunya-green-index-di-pasarmodal-1402913321. Diakses tanggal 10 April 2017.

Hariasih,Ni Putu Nonik dan Wirama,Dewa Gede. 2016. Analisis perbedaan Return Portofolio berdasarkan Model Indeks Tunggal dan Portofolio Random. E-Jurnal Ekonomi dan Bisnis Universitas Udayana,Bali,Indonesia.

Hartono,Jogiyanto. 2014. Teori Portofolio dan Analisis Investasi. Edisi Kesembilan. Yogyakarta: BPFEYogyakarta.

Hartono,Jogiyanto. 2016. Teori Portofolio dan Analisis Investasi. Edisi Kesepuluh. Yogyakarta: BPFEYogyakarta.

Rachmanto,Noki. 2002. Analisis Pembentukan Portofolio Optimal Saham di BEJ dengan Model Indeks Tunggal (Studi kasus saham perusahaan yang terdaftar di Bursa Efek Jakarta. Tesis Program studi Magister Manajemen Program pasca sarjana Universitas Diponegoro Semarang.

Risnawati,Yeprimar. 2009. Analisis Investasi dan Penentuan Portofolio Saham Optimal di Bursa Efek Indonesia (Studi Komparatif Penggunaan Model Indeks Tunggal dan Model Randompada Saham LQ-45). Jurnal Fakultas Ekonomi Universitas Sebelas Maret.
Samsul,Mohamad. 2006. Pasar Modal dan Manajemen Portofolio. Surabaya: Penerbit Erlangga.

Wahyudi,Dwi. 2001. Analisis Investasi dan Penentuan Portofolio Saham Optimal di Bursa Efek Jakarta (Studi Komparatif Penggunaan Model Indeks Tunggal dan Model Random pada Saham-Saham Indeks LQ-45 Periode 19972000). Program Magister Manajemen,Universitas Diponegoro,Semarang.

Wiyono,Gendro. 2011. Merancaang Penelitian Bisnis dengan analisis SPSS 17.0 \& SmartPLS 2.0. Yogyakarta: UPP BSTIM YKPN.

Website

www.finance.yahoo.com.Diaks es tanggal 22 Mei 2017.

Website www.idx.co.id.Diakses tanggal 24 Mei 2017.

Website

http://www.duniainvestasi.com /bei/prices/stock/SRI-

KEHATI.Diakses tanggal 25 Mei 2017.

Website

http://www.bi.go.id/id/moneter/bi7day-RR/data/Contents/Default.aspx. Diakses tanggal 29 Mei 2017. 